\title{
Vergifnis voor gehoorsaamheid (Ps. 130:4)
}

\author{
D.F. O'Kennedy \\ Dept. Ou en Nuwe Testament \\ Universiteit van Stellenbosch \\ STELLENBOSCH
}

\begin{abstract}
Forgiveness before obedience (Ps. 130:4)

This article investigates the concept of divine forgiveness as illustrated in Psalm 130, especially verse 4. Although many psalms compel us to conclude that the psalmist was considering material as well as spiritual salvation, this is not the case in Psalm 130. In Psalm 130:4 divine forgiveness is instrumental to the real purpose of "therefore you are feared" (NIV). One might have thought fearing God would be a ground for forgiveness. Verse 4, however, indicates that the gift of forgiveness precedes obedience to God. The purpose of forgiveness is that people should glorify God. Forgiveness sets the sinner free and enables him to serve God in obedience. The Old Testament concept of forgiveness has different dimensions. Psalm 130 signifies that forgiveness is essentially a matter in which God takes the initiative. Forgiveness does not depend on man's repentance. conversion, confession of guilt or a life of obedience.
\end{abstract}

\section{Inleidende opmerkings}

Die konsep vergifnis word op verskillende maniere in die Ou Testament beskryf. Vergifnis toon ' $n$ verband met baie ander teologiese konsepte of temas: versoening, verlossing, genade, berou en andere. Dit is gevolglik moeilik om "grense" vir 'n studie oor vergifnis in die Ou Testament te bepaal. Die vraag is: Wat is die beste manier om die konsep vergifnis in die Ou Testament te bestudeer? Vergifnis kan waarskynlik die beste verstaan word as dit in die gebedsliteratuur nagevors word.

Gebed vervul 'n belangrike rol in die uitbeelding van die aard van sowel God as die mens. Wat mense vir God in die gebed sê, openbaar hulle motiewe, houdings en moraliteit. Die aanspreek en beskrywing van God (bv. as vergewensgesind, regverdig, almagtig, ens.) in die gebed openbaar God se wesenstrekke (Balentine, 1993:48). Daar kan aanvaar word dat die wyse waarop die Ou-Testamentiese mens Goddelike vergifnis verstaan het, neerslag vind in die gebede. Hierdie aanname word bevestig deur die feit dat vergifnis as een van die sentrale temas in die gebedsliteratuur van die Ou Testament funksioneer (Kselman, 1992:831; Preuss, 1992:193). 
Die konsep vergifnis het heelwat raakpunte met ander Ou-Testamentiese konsepte en temas. Somtyds vind soveel oorvleueling plaas (bv. met versoening) dat dit moeilik is om 'n duidelike onderskeid te tref. Koch (1966:218) sê byvoorbeeld die volgende oor versoening en vergifnis: "Sühne is also mit Vergebung nah verwandt, oft identisch". 'n Moontlike definisie kan gevolglik nie die enigste fondament wees waarop navorsing oor die konsep vergifnis in die $\mathrm{Ou}$ Testament gebou word nie. Om hierdie rede behoort die verskillende Hebreeuse terme en uitdrukkings wat vergifnis in die Ou Testament beskryf, ondersoek te word.

Geleerdes is dit eens dat die konsep vergifnis in die Ou Testament die beste deur die term 0 uitgedruk word. Hierdie term kom uitsluitlik met God as subjek voor en word slegs met betrekking tot vergifnis gebruik (Stamm, 1940:47; Hausmann, 1986:860; Kselman, 1992:831). Die term 7 לo word in twee primêre kontekste in die Ou Testament gebruik: Eerstens word dit in die Priestergeskrif aangetref (Lev. 4:20, 26, 31, e.a.). Tweedens kom in die gebedsliteratuur voor: Eksodus 34:9; Numeri 14:19; 1 Konings 8:30, 34, 36, 39 en 50; 2 Kronieke 6:21, 25, 27, 30 en 39; Nehemia 9:17; Psalm 25:11; $86: 5 ; 103: 3$; 130:4; Klaagliedere 3:42; Daniël 9:9 en 19 en Amos 7:2. Buiten hierdie 21 OC-verwysings in die gebede van die Ou Testament is daar drie ander teksgedeeltes wat indirek na gebed of die antwoord op 'n gebed verwys: Numeri 14:20; 2 Konings 5:18 (twee keer) en 2 Kronieke 7:14.

Die bestudering van bogenoemde teksgedeeltes wys daarop dat die verstaan van vergifnis in die Ou Testament verskillende fasette het (vgl. O'Kennedy, 1994:262-263). Vervolgens gaan een van hierdie fasette aan die hand van Psalm 130:4 belig word. Die doel van hierdie artikel is nié om Psalm 130 in diepte te bestudeer nie; gevolglik word al die literêre en historiese kwessies nie in soveel detail bespreek nie. Psalm 130 word vanuit die hoek van Goddelike vergifnis ${ }^{1}$ bestudeer en die skopus van die artikel lê in afdelings $2.2,3$ en 4 .

\section{Literêre en historiese dimensie van Psalm 130:4}

\subsection{Literêre konteks}

Psalm 130 vorm deel van die groep pelgrims- of bedevaartsliedere wat strek vanaf Psalm 120 tot 134. Daar is verskillende verklarings oor die aard van

1 Die skrywer kon geen ander bron vind waarin Psalm 130 spesifiek vanuit hierdie hock bestudeer is nie. 
hierdie pelgrimsliedere. Waarskynlik is hierdie gebede ${ }^{2}$ gesing op die pelgrimstog van die plattelandse Jode na die tempel in Jerusalem (Burden, 1991:9-10). Psalm 130 word in die Christelike tradisie as die sesde van die sewe boetepsalms beskou (vgl. ook Ps. 6, 32, 38, 51, 102 en 143). Luther het weer hierdie Psalm as een van die "Pauliniese" Psalms beskryf, omdat die regverdiging deur die geloof so duidelik geleer word (Britz, 1982:53; Mays, 1994:405).

\subsection{Vertaling}

'n Moontlike eie vertaling van Psalm 130:3-4 lees soos volg:

As $U$ die sondes in aanmerking neem, Jah(we $)^{3}$, Here, wie sal bestaan? Maar by $U$ is daar vergifnis (חסליחה) ${ }^{4}$ sodat $U$ gevrees/gedien 5 mag word6; of daarom/gevolglik word $U$ gevrees/gedien.

Vers 4 word beklemtonend ingelei met die partikel כי net soos vers 3 ook beklemtonend ingelei word met die partikel (Briggs \& Briggs, 1907:465). Volgens Keet (1969:77) het כי כhier 'n sterk antitetiese bedoeling en kan dit met "maar" of "sekerlik" vertaal word. Die Nifal-vorm תררא (U gevrees/gedien mag word) is ongewoon en kom gewoonlik as 'n partisipium voor. Dit is klaarblyklik 'n voorbeeld van "ongewone" taalgebruik deur die bidder (Viviers, 1990:128).

Die vertaling van die laaste gedeelte van vers 4 is belangrik vir die verstaan van vergifnis. Marx (1981:130) stel voor dat dit as 'n voorwaardesin verstaan moet word. Dit beteken dat die bidder besef dat daar by Jahwe vergifnis is, mits Jahwe gevrees word. Hierdie siening moet op grond van grammatikale gegewens afgewys word. Die partikel למעל word in vers $4 \mathrm{~b}$ gebruik en nié die partikels

2 Baie van die Psalms kan as gebede getipeer word ten spyte van die feit dat hulle gesing is. Westermann (1989:19) meld ook dat in die vroee tyd die Psalms (veral die klaaggebede/liedere) waarskynlik meer opgesê as gesing is.

3 Verse 3 en 4 se eerste halwe versrecl vertoon eindrym en verklaar moontlik die keuse vir die afgekorte Godsnaam Jah (Viviers, 1990:128).

4 Die selfstandige naamwoord norg (vergifnis) word slegs in vers 4 en in Nehemia 9:17 en Daniël 9:9 gebruik. Psalm 130:4 is dic enigste teksverwysing in die Ou Testament waar dit in die enkelvoud gebruik word (Göbel, 1977:26).

5 Dit kan ook met "respekteer" vertaal word (Viviers, 1990:128).

6 Die LXX en die Griekse weergawes van Theodotion en Symmachus lees die werkwoord תור gevrees mag word) as תורת (jou wet). Daar kan egter met die Masoretiese teks volstaan word (Kraus, 1989:465) 


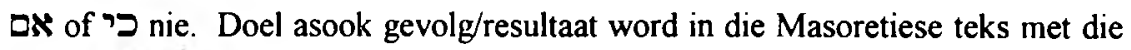
partikel למען ingelei en nié voorwaardesinne nie (vgl. Gen. 18:19; Eks. 4:5; 1 Sam. 15:5; Jer. 27:15; Ps. 125:3) (Brongers, 1973:89-90; Waltke \& O'Connor, 1990:91, 604, 639; Joüon, 1991:636-637).

Die meeste vertalings vertaal die partikel למען as doelgewend, dit wil sê "dat" of "sodat". Die 1983-Afrikaanse vertaling vertaal dit as 'n aanduiding van resultaat/gevolg, dit wil sê "daarom" (= om die rede). Dit is ook moontlik om 'n ander Afrikaanse woord te gebruik om die resultaat uit te druk. In die lig van die gebruik van למען in Psalm 30:13, 51:6 en Jeremia 36:37 kan dit ook met "gevolglik" (= dus/derhalwe) vertaal word.

By die eerste vertalingsmoontlikheid (doel) is daar 'n mate van verpligting te bespeur: God vergewe en dan móét die mens Hom dien. By die tweede moontlikheid (gevolg/resultaat) is daar 'n groter mate van dankbaarheid. God bewys eerste sy vergifnis en dit lei tot die mens se dien en verering van God. Die voorkoms en gebruik van die partikel למען asook die literêre konteks van Psalm 130 veronderstel sowel doel as resultaat as vertalingsmoontlikhede.

\subsection{Opbou en struktuur}

Psalm 130 is ' $n$ poëtiese gebed waarin die $3+2$ metrum die meeste voorkom (vgl. vs. 2-4, 8) (Allen, 1983:191). Dit is 'n fyn uitgewerkte gebed met herhaling van sleutelwoorde en die gebruik van chiasmes. Die sleutelwoorde sluit ondere andere in: die Godsname (Jahwe, Jah, Here); sondes (vs. 3, 8); ek/my siel wag (vs. 5, 6); hoop (= wag, vs. 5, 7); verlos (sing) (vs. 7, 8).

Daar is omvattende, maar ook kleiner, chiastiese patrone:

- vers 3-8: Sondes :: sondes

- vers 4-7: By $U$ is vergifnis :: By die Here is troue liefde ${ }^{8}$

- vers 5-7: Ek wag (hoop) ${ }^{9}$ : soos wagte op die môre :: soos wagte op die môre : ek wag (hoop)

- vers 5-6: My siel wag :: my siel wag op die Here

7 Die werkwoord $\pi$ oom ook in Jeremia 36:3 voor.

8 Die partikel כי kom in albei verse voor. In vers $7 \mathrm{~b}$ word dit redegewend (= want) gebruik en in vers $4 \mathrm{a}$ as adversatief (= maar) (Marrs, 1988:89).

9 Daar word aangesluit by die 1933/53-Afrikaanse vertaling wat sê: "ek hoop op sy woord". 
- vers $1 \mathrm{~b}-2$ : uit die dieptes : luister tog na my stem :: laat $\mathrm{u}$ ore luister : na my smekinge

- vers 7-8: Israel : verlossing :: verlos : Israel (Ceresko, 1976:308; Marrs, 1988:88-90; Viviers, 1990:126-132; Burden, 1991:73).

Geleerdes verskil oor die verdeling van Psalm 130. Op grond van 'n teksimmanente ondersoek verdeel Viviers (1990:125) die Psalm in agt stiges, vier strofes en twee stansas (vs. 1b-4; 5-8). ${ }^{10}$ Kraus (1989:466) verdeel Psalm 130 in drie hoofdele met die volgende temas:

1) Noodkreet van die geloof om hulp van God (vs. 1-4)

2) Die nuwe lewenstyl: lewe in hoopvolle verwagtinge (vs. 5-6)

3) Kultiese raamwerk (vs. 7-8)

Allen (1983:194), Burden (1991:73) en Mays (1994:405) verdeel Psalm 130 in vier stansas wat met Viviers se vier strofes ooreenkom (vs. 1b-2; vs. 3-4; vs. 56; vs. 7-8). 'n Moontlike eie verdeling met vier stansas lyk soos volg:

Opskrif

1) Roep om hulp

2) Vergifnis van sonde by Jahwe, die Here

3) Lewe in hoopvolle verwagting

4) Genade- en heilsverkondiging la

$1 b-2$

3-4

$5-6$

$7-8$

In die lig van die doel van die artikel sal die verdeling net kortliks gemotiveer word. Die opskrif in vers la tipeer die gebed as 'n bedevaartslied. Stilistiese kenmerke (ooreenstemmende suffikse, die gebruik van imperatiewe, ens.) en tematiese kenmerke ("hoor na my stem" en "laat u ore luister na die stem van my smekinge") groepeer verse $1 \mathrm{~b}-2$ saam. In hierdie eerste stansa word uit die dieptes tot God om hulp geroep. Stansa 2 (vs. 3-4) handel oor die tema van sonde en vergifnis. Hierdie verse kontrasteer die sonde van die mens met die vergifnis van God. Albei verse word beklemtonend ingelei met die partikels en S. Stansa 2 en 3 word van mekaar onderskei deur die gebruik van verskillende suffikse. Die suffikse in die tweede persoon enkelvoud is prominent by verse 3-4 (as $U, U$, by $U$ ), terwyl daar in verse 5-6 gefokus word op die eerste persoon (Ek, my siel). Daar is 'n verband tussen stansa 3 (vs. 5-6) en stansa 4 (vs. 6-7) deur die voorkoms van die woorde "wag/hoop op die Here". Die twee stansas moet egter van mekaar onderskei word deurdat stansa 3 verwys na die

10 Weiser (1965:773), Dahood (1970:235) en Van der Lugt (1980:417) verdeel Psalm130 ook in twee hoofdele of stansas: vs. 1-4 en 5-8. 
individu en stansa 4 na die volk Israel. In stansa 3 spreek die bidder die hoop uit dat hulp van die Here sal kom terwyl stansa 4 eerder as genade- en heilsverkondiging getipeer kan word.

\subsection{Gattung}

Daar word heelwat oor die Gattung van Psalm 130 bespiegel. Sommige geleerdes (Anderson, Dahood, Schmidt, Westermann, e.a.) tipeer dit as 'n individuele klaaglied of boetelied. Schmidt (1966:241-244) reken dat dit 'n individuele klaaglied is wat van die basiese vorm afwyk. Die bidder kla nóg oor krankheid of verdrukking deur vyande, nóg smeek hy om gesondmaking of redding. Die klag is volledig deur die skuldbelydenis vervang terwyl dit in ander gevalle slegs 'n deel van die klag uitmaak (vgl. Ps. 38:19; 69:6). In ander klaagliedere word die afstand van God as aanleiding of rede (ook as hoofmotief) van die klaaglied verstaan. In Psalm 130 is die afstand van God of sonde die eintlike nood van die bidder (Westermann, 1969:607). Dahood (1970:234) vergelyk Psalm 130 met Psalm 86 en stel dat die bidder in Psalm 130 moontlik 'n koning kan wees. Daar is egter nie genoegsame getuienis om Dahood se hipotese te aanvaar nie.

Ander geleerdes (Kraus en Weiser) is van mening dat daar elemente van die klaaglied sowel as van die danklied teenwoordig is. Psalm 130 vertel van 'n individuele gelowige wat bid terwyl hy deur die geloofsgemeenskap omring is. Volgens Kraus (1989:465) is dit egter ook moontlik dat verse 7-8 die woorde is van 'n bidder wat gerig is tot die gemeenskap. In hierdie geval moet daar aangeneem word dat die verlossing reeds geskenk is en dat die hele Psalm 'n danklied is. Hierdie siening word versterk indien die werkwoorde in vers $1 \mathrm{~b}$ en 5 as verlede tyd gesien word. Daar word dan teruggekyk op verlossing wat in die verlede geskenk is. Kraus wil egter nie 'n keuse tussen dank en klag maak nie.

In verse 7 en 8 is daar moontlik elemente wat kan dui op 'n klag van die volk en nié slegs dié van die enkeling nie (Seybold, 1979:254). Göbel (1977:26) glo dat verse 1-6 oorspronklik na die enkeling in Israel verwys het, maar dat die "ek" in die huidige teks na die gemeente verwys. Volgens haar het die toevoeging van verse 7-8 die oorspronklik individuele Psalm tot 'n kollektiewe Psalm omgebou.

Dit is moeilik om 'n keuse ten opsigte van die Gattung te maak. Hierdie Psalm bevat elemente van sowel die klag (volk en enkeling) as die dank. Die smeking om vergifnis staan egter sentraal; gevolglik kan dit ook as 'n vertrouensgebed of smeking om vergifnis teen die agtergrond van die klag getipeer word (vgl. Westermann, 1989:117; Viviers, 1992:72). 


\subsection{Sitz im Leben}

Eissfeldt (1965:120) beskou Psalm 130 as nie-kulties vanweë sy persoonlike woordgebruik en diep godsdienstige agtergrond. Fohrer (1968:292) definieer die Psalm as 'n na-eksiliese persoonlike toewydingslied sonder enige kultiese assosiasies. Schmidt $(1966: 242,249)$ sien die Psalm as losstaande van die kultus. Die "weitgehenden Erweichungen" wat die vormopbou aantoon, kan slegs verklaar word wanneer die Psalm van die kultus losgemaak word.

Aan die ander kant reken Van As (1961:33) dat 'n priesterlike instelling ten grondslag van die Psalm lê. Moontlik is daar deur middel van 'n deklaratiewe verklaring duidelik aan die bidder gestel dat God sy sonde vergewe het. Burden (1991:78) sluit by hierdie siening aan en brei dit verder uit. Hy reken dat Psalm 130 wel in die kultus gebruik is. Die eerste koor sing verse $1 b-6$ namens die gemeente en die tweede koor moedig hulle in verse 7-8 an om vas te hou aan die hoop. Aanvanklik het die bidder ' $n$ orakel ontvang dat sy sonde vergewe is. Hierdie boodskap van hoop uit die priester se mond is deur die koor gehoor en gesing as ' $n$ belofte van verlossing vir Israel. Lamparter (1959:310) opper die moontlikheid dat Psalm 130 'n gebed is wat tydens die sonde- of skuldoffer gebid is.

Alhoewel sommige geleerdes (Eissfeldt, Fohrer en Schmidt) die Psalm as niekulties beskou, is daar geen getuienis wat 'n kultiese agtergrond uitsluit nie. In die eerste plek het ' $n$ mens te make met ' $n$ biddende enkeling wat hom in uiterste nood tot God wend. Die fokus in Psalm 130 is nie slegs op die individuele bidder nie, maar op die individu wat deel is van die gemeenskap. Hierdie individuele bidder se gebedservaring is deurgegee aan die geloofsgemeenskap en word sodoende deel van hulle liturgie. Geen detail van die bidder en sy nood word verstrek nie; hy is 'n soort incognito-bidder en juis daarom kan hy as verteenwoordiger van die kultiese gemeenskap voor God staan (vgl. Croft, 1987:147).

\subsection{Samestelling, redaksie en datering}

Seybold (1979:254) glo dat vers 4 nie 'n oorspronklike gedeelte van die gebed is nie. Volgens hom is vers 4 ' $n$ teologiese refleksie en interpretasie tussen die retoriese vraag in vers 3 en die "wag op die vervulling van sy woord" in vers 5 . Daar is egter geen historiese of grammatikale getuienis wat hierdie standpunt ondersteun nie.

Daar is sommige geleerdes (Briggs \& Briggs, Schmidt, Seybold, Westermann, e.a.) wat verse 7 en 8 as 'n latere byvoeging beskou. Westermann (1969:609) sê dat slegs die lof vir God se verlossende genade (vs. 7ab-b) deel van die oorspronklike materiaal is. Volgens hom is vers $7 \mathrm{aa}$ en 8 'n latere byvoeging deur die gemeenskap op grond van die versameling van Psalın 120 tot 134 . 
Schmidt (1966:251-252) reken dat verse 7 en 8 as 'n geheel 'n byvoeging tot die res van die Psalm is. Volgens hom is dit 'n latere byvoeging waarin die individuele klaaglied in die godsdiens van die kultusgemeente opgeneem word. Die bede om verlossing is 'n eienskap van hierdie byvoegings (vgl. Ps. 25:22 en $34: 23)$.

Aan die ander kant beklemtoon Anderson (1977:877), Allen (1983:194), Marrs (1988:90) en Viviers (1992:72) dat verse 7-8 op grond van teologiese en stilistiese ooreenkomste 'n noue verband met verse 1-6 het. Ceresco (1976:308) wys daarop dat verse 5-7 'n chiastiese patroon vorm. Hierdie patroon word in verse 7 en 8 voortgesit en getuig teen die siening van verse 7 en 8 as 'n latere glos. Op grond van strukturele en teologiese getuienis kan aanvaar word dat verse 7-8 ' $\mathrm{n}$ wesentlike deel van die Psalm is.

Dahood (1970:234) reken dat indien daar 'n bepaalde korrelasie tussen Psalm 86 en 130 is, Psalm 130 pre-eksilies gedateer moet word toe Israel nog 'n koning gehad het. Die gebruik van die woord "koning" impliseer nie noodwendig dat die Psalm pre-eksilies is nie. Na-eksiliese Israeliete kon ook na 'n koning verwys het.

Psalm 130 kan waarskynlik as na-eksilies gedateer word vanweë die taalgebruik en spesifieke teologiese temas, byvoorbeeld die tema van vergifnis (Schmidt, 1966:242; Briggs \& Briggs, 1907:464; Allen, 1983:195; Kraus, 1989:466; Westermann, 1989:118).

\section{Teologiese dimensie van vergifnis}

Vers 4 is die enigste vers in Psalm 130 waarin 'n spesifieke term vir vergifnis voorkom; tog reken Westermann (1989:117) dat die hele Psalm as 'n smeking om vergifnis getipeer kan word. Daar skemer slegs in verse 1-2 'n element van klag deur en die laaste gedeelte van die Psalm is 'n uitdrukking van hoop dat die vergifnis geskenk sal word.

Die bidder van Psalm 130 laat sy gebed vanaf 'n dieptepunt tot 'n hoogtepunt ontwikkel. Vanaf die godverlatenheid van die "dieptes" word daar oorgegaan tot 'n belydenis van sonde en die erkenning van God se vergewensgesindheid. Hierdie belydenis loop uit op 'n hoopvolle afwagting op Jahwe se genadige toewending, en 'n klimaks waar Israel van Jahwe se volledige verlossing verseker word. Die bidder hou sy eie ervaring as voorbeeld aan die gemeenskap voor (Viviers, 1990:136).

Die kemvraag is: wat is die inhoud van die vergifnis in hierdie Psalm? In Psalm 130 is vergifnis instrumenteel tot die eintlike doel: "sodat God gevrees/gedien mag word". Menslik gesproke, moes dit eintlik in 'n omgekeerde volgorde 
gestaan het. 'n Mens sou dink dat die dien van God 'n grond of rede moet wees vir die vergifnis van God. Hier is dit duidelik dat die gawe van vergifnis die gehoorsaamheid voorafgaan (Brueggemann, 1984:104). Die doel van God se vergifnis is dat mense ontsag vir Hom sal hê. Vergifuis stel die sondaar in staat om God te eer deur Hom te dien (Burden, 1991:75). Indien God die mens straf vir sy sonde, sal die mens Hom vrees as die streng uitdeler van reg en geregtigheid. Indien God egter bereid is om te vergewe, sal mense 'n heilige vrees vir Hom hê en 'n begeerte om Hom te aanbid (Keet, 1969:77).

Alhoewel God se vergifnis sentraal staan, meld Göbel (1977:26) dat סליחה nie met "goedkoop genade" te doen het nie, maar met God se majesteit. Die bidder moet "roep uit die dieptes" (vs. 1) om God aan sy genade te herinner. Aan die ander kant gee die beloftes van vergifnis vir hom die moed om God uit die dieptes aan te roep. Die bidder kon net sowel sy sonde vir homself gehou het en nie tot God gebid het nie. Ten spyte van die mens se "roep uit die dieptes" beklemtoon Psalm 130 dat vergifinis 'n onbegryplike wonder van God is waar Hy sy goedheid aan die sondaar bewys. Vergifinis is die handewerk van God. God is al een wat die gesag het om die sondes van die mens te kan vergewe. Die volk Israel het hierdie afhanklikheid van God op verskillende maniere in hulle geskiedenis geleer, veral in die Ballingskaptyd (Lamparter, 1959:311; Mays, 1994:406-407).

Daar word dikwels in die Ou Testament geredeneer dat God sy liefde met uiterlike magsbewys (bv. verlossing uit siekte of nood) ten toon moet stel sodat die heidene respek vir Hom kan hê. Die vergifinis gaan dus met fisiese herstel gepaard. In Psalm 130 is daar geen direkte verwysing na materiële of geestelike verlossing nie. Hierdie Psalm verskil in hierdie opsig van die ander Psalms (vgl. Ps. 25, 32, 51, 79, 103) waar dit wel die geval is (McKeating, 1965:73).

Die nood van die bidder in Psalm 130 word met die woord "dieptes" in vers 1 uitgedruk. Die bidder is in ernstige moeilikheid, maar die Psalm sê nie watter soort moeilikheid dit is nie. Sommige verklaarders reken dat hy dodelik siek was en dat hy in die Psalm erken dat sy lyding die straf op sy sonde is. Ander verklaarders dink dat "die dieptes" na die omringende waters van die doderyk (שיל) verwys (vgl. Ps. 88:3-4; Jes. 51:10; Eseg. 27:34) (Burden, 1991:74; Mays, 1994:406).

Die bidder van Psalm 130 beskou wel sy persoonlike lyding as die gevolg van sy eie wandade; tog vind hy berusting in die feit dat Jahwe 'n God is wat vergewe. Hierdie Goddelike kwaliteit styg uit bo die mens se sondigheid. Die retoriese vraag in vers 3 impliseer eintlik 'n negatiewe antwoord. Indien Jahwe boekhou van die mens se sondes en dit straf, sal niemand God se oordeel ontvlug nie; tog herinner die bidder God daaraan dat hy nie die dood van 'n sondaar verlang nie, maar die herstel tot lewe - alles ter wille van die eer van God (Allen, 1983:195). 
'n Belangrike element wat in vers 4 asook in die res van die Psalm voorkom, is die wag op God se vergifnis. Die roep om vergifnis is tegelyk ook 'n afwagting daarvan. Die roep tot God in vers 1 en 2 word begrond met die belydenis in vers 4: "Maar by $U$ is daar vergifnis". Net so word die wag op Jahwe se vergifnis (vs. 5-6) begrond in die belydenis van vertroue in verse 7 en 8: "... by die Here is daar troue liefde, by Hom is die verlossing seker. Hy alleen sal Israel verlos van al sy sondes" (Van der Merwe, 1983:56).

Verse 7 en 8 dui verder op 'n verband tussen vergifnis en verlossing. Die genade van God lei tot vergifnis en verlossing van sondes. Vers 8 verstaan die verlossing as sondevergifnis. Hierdie vers is die enigste teksgedeelte in die Ou Testament wat direk en onmiskenbaar van "verlossing uit sonde" praat (Stamm, 1940:92). Psalm 130 stel dit duidelik dat die manier waarop God vergewe deur die verlossing (eintlik losprys) van sondes geskied (Schmidt, 1966:252; Burden, 1991:77).

\section{Slot}

Vergifnis word soms in die Ou Testament beskryf as God se genadige antwoord nadat die mens homself bekeer het (vgl. Jes. 55:7; Jer. 36:3). Psalm 130:4 toon aan dat vergifnis in wese ' $n$ saak is waarin God die inisiatief neem. Vergifuis is nie eerstens afhanklik van die mens se berou, bekering, skuldbelydenis of lewe van gehoorsaamheid nie.

In Psalm 130:4 is dit duidelik dat die gawe van vergifnis die mens se gehoorsaamheid voorafgaan. Die doel van God se vergifnis is dat mense ontsag vir Hom sal hê. Vergifnis stel die sondaar in staat om God in gehoorsaamheid te dien. Die bidder/s van Psalm 130 ervaar dat God al persoon is wat sondes kan vergewe en mense vry maak om Hom met oorgawe te dien.

Psalm 130 verskil van die res van die Psalms waar vergifnis met fisiese herstel gepaard gaan (vgl. Ps. 25, 32, 51, 79, 103). In Psalm 130 word nie gebid dat God sy vergifnis moet bewys deur die skenk van gesondheid of redding uit nood nie. Hier word slegs gebid dat God geestelike verlossing moet skenk, dit wil sê verlossing van sonde (vgl. Ps. 130:3, 8). Alhoewel verskillende dimensies van vergifnis in die Ou Testament voorkom, beklemtoon Psalm 130:4 die dimensie van vergifnis as die wegneem van sonde en uitwissing van skuld.

\section{Bibliografie}

ALLEN, L.C. 1983. Psalms 101-150. Waco, Texas : Word Books.

ANDERSON, A.A. 1977. The book of Psalms, Vol. 2 (73-150). Greenwood: Attic Press.

BALENTINE, S.E 1993. Prayer in the Hebrew Bible. The drama of divine-human dialogue Minneapolis : Fortress Press. 
BRONGERS, HA. 1973. Die Partikel למע in der hebräischen Sprache. Oudtestamentische Studièn, 18:84-96.

BRIGGS, C.A. \& BRIGGS, E.G. 1907. The book of Psalms, Vol. Il Edinburgh : Clark.

BRITZ, P.J. 1982. Hesed in die Psalms. Stellenbosch : US. (M.Th.-verhandeling.)

BRUEGgEMANN, W. 1984 The message of the Psalms. Minneapolis : Augsburg Publishing House.

BURDEN, J J. 1991. Psalms 120-150. Kaapstad : NG Kerk-Uitgewers.

CERESCO, A.R. 1976. The chiastic word pattern in Hebrew. Catholic Biblical Quarterly, 38:303-311.

CROFT, J L. 1987. The identity of the individual in the Psalms. Sheffield : JSOT Press.

DAHOOD, M. 1970. Psalms III:101-150. Garden City, New York : Doubleday.

EISSFELDT, O. 1965. The Old Testament: An introduction (translated from the 3rd German edition) New York : Harper and Row.

FOHRER, G. 1968. Introduction to the Old Testament (translated by D.E. Green). New York : Abingdon Press.

GOBEL, C.H. 1977. "Den bei dir ist die Vergebung" - סלח im Alten Testament. Theologische Versuche, 8:21-33.

HAUSMANN, J 1986. s.v. סל Theologisches Worterbuch zum Alten Testament, V:859867.

JOÜON, S.J. 1991. A grammar of Biblical Hebrew, vol. I and II (translated and revised by T. Maraoka). Roma : Editrice Pontificio Instituto Biblico

KEET, C.C. 1969. A study of the Psalms of Ascents: A critical and exegetical commentary upon Psalms CXX to CXXXIV. London: The Mitre Press.

KOCH, K. 1966. Sühne und Sündenvergebung um die Wende von der exilischen zur nachexilischen Zeit. Evangelische Theologie, 26:217-239.

KRAUS, H.J. 1989. Psalm 60-150. Minneapolis : Augsburg Publishing House.

KSELMAN, J.S. 1992. s.v. Forgiveness (OT). Anchor Bible Dictionary, Vol. II: 31-833.

LAMPARTER, H. 1959. Das Buch der Psalmen: Psalm 73-150. Stuttgart : Calwer Verlag.

MARRS, R.R. 1988. A cry from the depths. Zeitschrift fiir alttestamentliche Wissenschaft, 100:81-90.

MARX, S. 1981. 'n Struktuur-analities-eksegetiese studie oor die besondere aard en betekenis van die bedevaartsliedere: Psalm 120-134. Stellenbosch : US. (M.Th.verhandeling.)

MAYS, J.L 1994. Psalms. Louisville : John Knox Press.

McKEATING, H. 1965. Divine forgiveness in the Psalms. Scoltish Journal of Theology, 18:69-83.

O'KENNEDY, D.F. 1994 Die gebed om vergifnis. Stellenbosch : US. (D.Th.-proefskrif.)

PREUSS, H.D. 1992. Theologie des Alten Testaments, Band 2. Stuttgart : Verlag W. Kohlhammer. 
SCHMIDT, W.H. 1966. Gott und Mensch in Ps 130. Theologische Zeitschrift, 22:241-253.

SEYBOLD, K. 1979. Die Redaktion der Wallfahrtspsalmen. Zeitschrift fiur alttestamentliche Wissenschaft, 91:247-268.

STAMM, J.J. 1940. Erlösen und vergeben im Altem Testament. Bern : A. Francke A-G Verlag

VAN AS, J.J. 1961. Skuldbelydenis en genadeverkondiging in die Ou Testament. Utrecht : Elinkwijk.

VAN DER LUGT, P. 1980. Strofische structuren in de bijbels-hebreeuse poezie. Kampen Kok.

VAN DER MERWE, M.A.V. 1983. Psalm 130. (In Burger, C.W., Müller, B.A. \& Smit, D.J., reds. Woord teen die Lig 1/2: Riglyne vir lydensprediking Kaapstad : NG KerkUitgewers. p. 52-57.)

VIVIERS, H. 1990. 'n Teksimmanente ondersoek na die samehang van die Ma'alôt-Psalms (Ps. 120-134). Pretoria : UP. (D.D.-proefskrif.)

VIVIERS, H. 1992. Trust and lament in the Ma'alôt Psalms. Old Testament Essays, 5:6477.

WALTKE, B.K. \& O'CONNOR, M. 1990. An introduction to Biblical Hebrew syntax. Winona Lake, Indiana : Eisenbrauns.

WEISER, A. 1965. The Psalms (translated by H. Hartwell). Second Impression. London : SCM Press.

WESTERMANN, C. 1969. Busstag: Psalm 130. (In Eicholtz, G., ed. Herr, tue meine Lippen auf. Band 5. Wuppertal-Barmen : Emil Müller Verlag. p. 606-612.)

WESTERMANN, C. 1989. The living Psalms. Grand Rapids, Michigan : Eerdmans. 